\section{Defining the common ground}

\author{
Michael B. Usher
}

Ecological Economics: The Journal of the International Society for Ecological Economics. Editor-in-chief R. Costanza. Elsevier. 6/yr. US and Canada \$265, elsewhere Dfl. 440.

ECONOMICS has been a part of many applied environmental degree courses, such as forestry, for the past 30 years or more, but it is a subject that is missing from most ecology courses. Why is this? Is it that ecology as a science has divorced itself from the social sciences, or is there really so little common ground? Many scientific advances have been achieved by the synergistic interactions between two disciplines; can ecology and economics (both incidentally derived from the same Greek word) have such a future?

Ecological Economics was selected as a title in preference to Economic Ecology or Ecology and Economics, but it is clear that the field needs definition. Paul Ehrlich in the first issue quotes a survey in which graduate economics students did not mention ecology at all in their lists of out-of-subject reading. We do not know whether ecology graduate students treat economics similarly. Because economic decisions often have ecological implications, should this new subject of ecological economics be included in the training of both economists and ecologists?

The journal has an editorial team of 45, with membership from the United States (44 per cent), nine European nations ( 38 per cent) and five other nations ( 18 per cent). The papers, however, are more strongly biased towards the United States with 65 per cent of the authors coming from there, 22 per cent from six European nations and 13 per cent from five other nations. Do these figures tell us anything about the world distribution of research and expertise in ecological economics, about the activities of the editorial board, or simply about the writing habits of the researchers?

The journal is going to have to steer a difficult path between environmental and ecological economics. Papers on chemical emissions, environmental accounting, water quality, nonrenewable resources and energy resources, have the wider environmental perspective. Other papers focusing on wetlands, nitrogen and agricultural land, tropical agriculture, and the preservation of species, crop varieties and genetic diversity, have a more clearly defined ecological per- spective. I welcome such papers because they provide an insight into an area of applied ecology that has too frequently been neglected. The editorial team must ensure that they guide the journal into what is truly ecological economics, avoiding its becoming another venue for publication of papers in environmental economics. Sustainability, lying on the boarder line of ecological and environmental thought, is clearly a subject well worth covering. A stringent editorial policy will be needed if this new journal is to develop and guide the field of ecological economics, as well as demonstrating its importance and excitement to students of ecology and economics alike.

Michael B. Usher is at the Nature Conservancy Council for Scotland, 2 Anderson Place, Edinburgh EH6 5NP, UK.

\section{Microbes at work}

\section{W. Bernard Betts}

Biodegradation. Editors-in-chief R. S. Hanson, T. Leisinger, B. E. Rittmann, A. H. Stouthamer and W. Verstraete. Kluwer. 4/yr. Dfl. 340, £115.50, $\$ 173$ (institutional); Dfl. $190, £ 64.50$, $\$ 99.50$ (personal)

BIODEGRADATION is a recent (1990) and timely offspring of Kluwer's Antonie van Lecuwenhoek, publishing original research papers and invited reviews on the detoxification, recycling, amelioration or

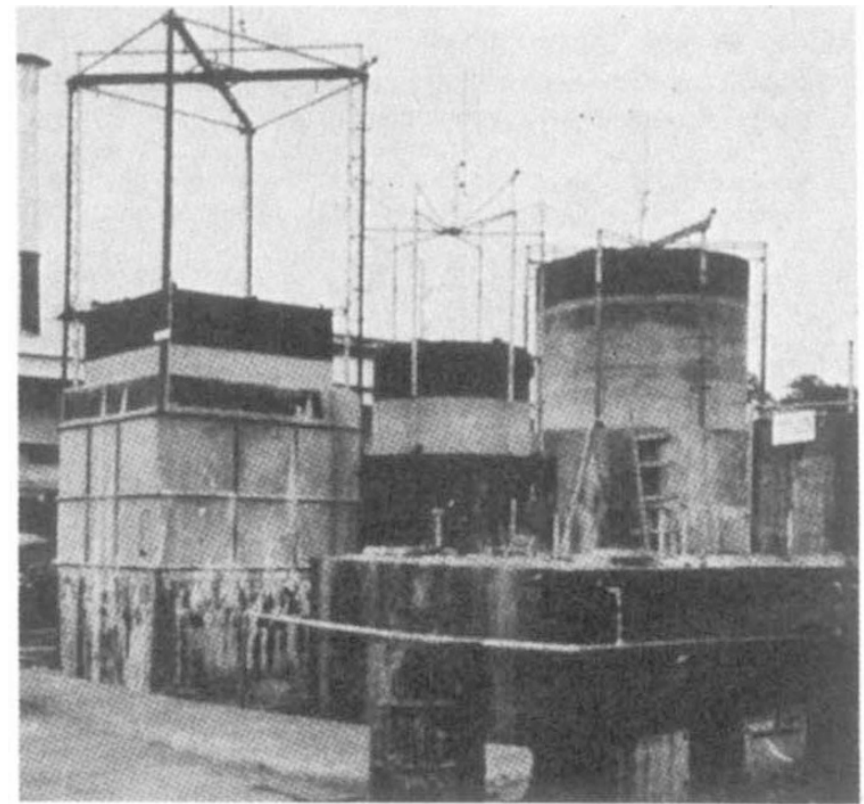

Bio-gas plants were developed in Germany during the Second World War. This large plant in Manila converts the manure of 7,500 pigs into gas. (From Paper Heroes. Appropriate Technology: Panacea or Pipe Dream? by Witold Rybczynski. Published in paperback by Penguin, price $\$ 9.95$.) treatment of waste materials and pollutants by naturally occurring microbes (including associations) or recombinant microorganisms. The scope is broad and includes fundamental biodegradation biochemistry, physiology and genetics, modelling and scale-up of biotreatment systems for specific applications, and the development of international standards encompassing economic and legal aspects of waste treatment.

The editorial board looks impressive, comprising international experts from well-selected and important areas of biodegradation research. Indeed, the air of quality carries through, and papers published so far have been of a very high standard. The first special issue on the physiology of biodegradative microorganisms (guest editor Colin Ratledge) was an especially interesting combination of reviews examining some of the fundamental research supporting the more applied aspects of biodegradation. I look forward to special issues appearing in subsequent volumes, although the requisitioning of two issues for this purpose seems rather extravagant and leaves room for around only 14 research papers per year at current publication rates.

The journal is bright and attractive, with a large-format double-column style. Clarity is excellent and an unusual and distinctive cover logo completes the impression of good quality scientific modernism.

As the editorial in the first issue emphasizes, biodegradation is an important discipline. Much basic research is still needed to exploit the ability of microbes to degrade both recalcitrant and xenobiotic compounds. In addition, bioremediation systems for the wide range of potential pollution problems are far from established. The journal should provide a specialized forum for the publication of research dedicated to this expanding area, and will perhaps assist authors to publish their results more quickly; the field is currently served by many of the nonspecialist journals and long delays are often involved before articles appear in print. But do not expect to have your paper published so rapidly, as the low number of annual issues and the emphasis on detailed, 